University of Wollongong

Research Online

Faculty of Social Sciences - Papers (Archive) Faculty of Arts, Social Sciences \& Humanities

2010

Community-based child abuse prevention: Outcomes associated with a differential response program in California

Amy Conley Wright

University of Wollongong, acwright@uow.edu.au

Jill Duerr Berrick

University Of California, Berkeley

Follow this and additional works at: https://ro.uow.edu.au/sspapers

Part of the Education Commons, and the Social and Behavioral Sciences Commons

Research Online is the open access institutional repository for the University of Wollongong. For further information contact the UOW Library: research-pubs@uow.edu.au 


\title{
Community-based child abuse prevention: Outcomes associated with a differential response program in California
}

\begin{abstract}
Traditionally, the American child welfare system intervenes in cases of evident and severe maltreatment. Families in need of help, but who have not reached a crisis, are excluded from typical services. Some suggest that if these families were served, few would be rereferred to the child welfare system.

California's Differential Response (DR) has three tracks, of which "Track 1" targets families screened out of child protective services (CPS) and refers them to agencies that provide voluntary, home-based services and referrals. This study examined child-welfare trajectories for families receiving Track $1 \mathrm{DR}$ services in one California county. Using survival analysis, treatment group children $(N=134)$ were compared to children eligible for services but denied due to program capacity (comparison group $\mathrm{N}=$ 511). Findings suggest no statistically significant differences between groups on the likelihood of a rereport following program participation, timing of maltreatment reports, or report investigations. The ability to draw strong conclusions from this study, however, is limited by selection bias because prior child maltreatment reports were more common in the treatment group. The intervention may provide families with important supports, but evidence for maltreatment prevention may not be supported. Future studies should examine potential effects on a range of family domains.
\end{abstract}

\section{Keywords}

era2015, response, associated, outcomes, prevention, program, california, abuse, differential, community, child

\author{
Disciplines \\ Education | Social and Behavioral Sciences
}

\section{Publication Details}

Wright, A. C. \& Duerr Berrick, J. (2010). Community-based child abuse prevention: Outcomes associated with a differential response program in California. Child Maltreatment, 15 (4), 282-292. 
RUNNING HEAD: Community-based child abuse prevention

\title{
Community-based child abuse prevention: Outcomes associated with a differential response program in California
}

\author{
Amy Conley, MSW, Ph.D \\ Assistant Professor \\ Child and Adolescent Development Department \\ College of Health and Human Services \\ San Francisco State University \\ 1600 Holloway Avenue - SCI 389 \\ San Francisco, CA 94132 \\ 415-405-2831 \\ aconley@sfsu.edu \\ Jill Duerr Berrick, MSW, Ph.D. \\ Professor \\ University of California at Berkeley \\ School of Social Welfare \\ 120 Haviland Hall \\ Berkeley, CA 94720-7400 \\ 510-642-4341 \\ dberrick@berkeley.edu
}

This project was supported by a curriculum-development grant funded by the California Social Work Education Center (CalSWEC) and the California Department of Social Services and a research grant from the Fahs-Beck Fund. Thanks to Anna Geer for her contribution to this study, and to the administrators and staff of Alameda County Social Services Agency, Every Child Counts First 5 Alameda County, and the Another Road to Safety program for their participation and assistance. 


\begin{abstract}
Traditionally, the American child welfare system intervenes in cases of evident and severe maltreatment. Families in need of help, but who have not reached a crisis, are excluded from typical services. Some suggest that if these families were served, few would be re-referred to the child welfare system. California's Differential Response (DR) has 3 tracks, of which 'track 1' targets families screened out of CPS and refers them to agencies that provide voluntary, homebased services and referrals. This study examined child welfare trajectories for families receiving track $1 \mathrm{DR}$ services in one California County. Using survival analysis, treatment group children $(N=134)$ were compared to children eligible for services, but denied due to program capacity (comparison group $N=511$ ). Findings suggest no statistically significant differences between groups on the likelihood of a re-report following program participation, timing of maltreatment reports, or report investigations. The ability to draw strong conclusions from this study, however, is limited by selection bias because prior child maltreatment reports were more common in the treatment group. The intervention may provide families with important supports, but evidence for maltreatment prevention may not be supported. Future studies should examine potential effects on a range of family domains.
\end{abstract}


In states across the country, child welfare systems are undergoing historic reform processes intended to promote safety and permanency through early intervention. In California alone, roughly half a million children are reported to public child welfare agencies for child maltreatment each year (Needell et al., 2009). But under the current system, about half of these referrals receive little more than a formal investigation without additional services (J. Magruder, personal communication, June 11, 2009), and among cases reported to the hotline each year, approximately one-third are re-reported within a 12 month timeframe (Needell, et al., 2009). Taken together, these figures suggest a system in which only the relatively severe cases receive services and to which some families may be repeatedly referred before receiving the assistance they need. Critics have long voiced concerns that low- to moderate-risk families are the least well-served of all families coming to the attention of child welfare agencies. For these families, the typical levers of child welfare intervention are overly-intrusive, inappropriately coercive, and inadequately connected to the community (Waldfogel, 1998).

Differential Response (DR)—also known as alternative response, multi-track response, and dual-track response-is designed in part to address this issue. Comprised of three main characteristics, DR screens by risk level, provides voluntary case management and other services to low- and moderate risk families, and offers a non-punitive and non-authoritarian approach. Differential Response is catching the attention of policy makers and child welfare administrators throughout the country. According to one study, as of 2003, approximately twenty states had begun incorporating DR into their child welfare systems (U.S. Department of Health and Human Services, 2003); another study suggested that 11 states had implemented the program statewide (Kaplan \& Merkel-Holguin, 2008). 
The predominant version of DR currently being implemented in California involves three "tracks" or service responses. Moving away from the substantiated/unsubstantiated distinction, the new approach offers services to families based on their assessed level of risk. Track 1, called "Community Response," is for cases that do not meet the statutory definition of child maltreatment, yet where families are experiencing problems which could be addressed by services from a community-based organization. Track 2, "Child Welfare Services and Community Response," involves a partnership between the county child welfare agency and a community agency to provide services for families whose reports meet the legal definition of maltreatment but in which the risk of future child maltreatment is deemed low-to-moderate and the family agrees to voluntary participation. "Child Welfare Services Response," or Track 3, is simply the traditional child welfare response, in which the county agency provides voluntary or court-mandated services to families deemed at moderate to high risk of future maltreatment (Foundation Consortium, 2005).

Alameda County is the pilot site of California's first Differential Response program, Another Road to Safety (ARS). The ARS program resembles the predominant California approach, offering 3 service tracks. The study reported here focuses only on families in Track 1 . At the time of this study, program resources were limited, thus only families living in targeted zip codes with high rates of child maltreatment reporting were eligible for services; services were also limited to families with children ages 0-5 or a pregnant mother. This study examined child welfare system involvement for families who received the ARS intervention. The null hypothesis states that there would be no difference in child welfare outcomes for study subjects participating in ARS compared to subjects not participating in ARS. All clients in one program site formed the treatment group $(N=134)$. A comparison group was constructed of all families 
reported for child maltreatment in the same timeframe and zip codes who were eligible for services, but were not referred because of program capacity $(N=511)$. Survival analysis was used to compare subsequent rates of re-report, investigation, and substantiated re-report. Survival analysis is suitable for a study of this nature as the data were modeled to examine time from origin (representing referral to the ARS program for the treatment group and index report for the comparison group) to event (subsequent child welfare incident).

\section{Review of the literature}

In states with some experience providing Differential Response, unique approaches have been taken in the organization and delivery of services. Case management may be provided through public child welfare agencies (Missouri, Virginia, North Carolina, Florida), through community-based agencies contracted by the public child welfare agency (Washington, Michigan, South Carolina), or may be mixed in the state and may depend on the county (Minnesota, Louisiana) (National Child Welfare Resource Center for Family-Centered Practice, 2001). One worker may stay with a case from the assessment through service delivery phase, or a case may be reassigned after assessment. The varied nature of program approaches must be kept in mind when interpreting research findings.

Evaluations of DR are emerging across various states and localities (see: Center for Child and Family Policy, 2004; English et al., 2000; Kirk, 2008; Loman \& Siegel, 2004a; Loman \& Siegel, 2004b; Virginia Department of Social Services, 2003). These studies of Differential Response focus on children and families served in what California would term "Track 2" -families "opened" for services by the public child welfare agency, but served voluntarily by DR rather than involuntarily through conventional child welfare practice. All of the studies incorporate a cohort design in the study of outcomes; some also supplement their approach with 
qualitative measures to assess the experiences of workers, supervisors, community members, and families. One study includes a cost analysis (Loman \& Siegel, 2004a). Most of the studies include comparison groups, either through matching a pilot and business-as-usual county/community (Loman \& Siegel, 2004a; English et al., 2000, Center for Child and Family Policy, 2004) or through random assignment (Loman \& Siegel, 2004b). The main outcomes assessed by these studies are risk of re-report, risk of investigation, and risk of out-of-home placement. Success is measured by rates of child welfare involvement that are no greater than they might have been using the traditional model of child welfare intervention, and uncompromised child safety.

Findings from studies of Differential Response are equivocal. With reference to the comparison group, families receiving DR were statistically less likely to be re-reported in two studies (Loman \& Siegel, 2004a; Loman \& Siegel, 2004b), while no differences were observed in other evaluations of DR (Center for Child and Family Policy, 2004; English et al., 2000). Findings for placement in out-of-home care were also mixed (Loman \& Siegel, 2004b; Loman \& Siegel, 2004a; English et al., 2000). In addition to these individual state studies, the U.S. Department of Health and Human Services (2005) conducted a study on case-level data reported through the National Archive of Child Abuse and Neglect Data System for six states (Kentucky, Minnesota, Missouri, New Jersey, Oklahoma, and Wyoming) that offer both DR and traditional investigation. Six months subsequent to the initial report, re-report rates appeared to be similar between those cases assigned to traditional investigation or DR, with the exception of Oklahoma, where rates of subsequent reporting were lower for families receiving Differential Response.

Differential Response evaluations have typically focused on outcomes associated with child welfare system involvement, with less attention to family changes in other domains. A 
study by Kirk (2008) attempted to examine other factors associated with family health and wellbeing and found minor to modest positive changes for families participating in Differential Response. No comparison group was included in the study, however, diminishing the utility of the study findings.

The mixed findings relating to child welfare involvement may be indicative of problems of targeting. Although designed for families at low-to moderate risk, the exigencies of child welfare agencies, and the need to triage cases pushes many high risk families into DR where researchers caution - the approach may not be appropriate. Efforts by the American Humane Association (Kaplan \& Merkel-Holguin, 2008) to better specify the program components required to truly claim the Differential Response mantel may be helpful as agencies attempt to determine how best to serve the range of clients referred for child maltreatment.

This study differs from existing research on DR as it examines program effects for families served in "Track 1" rather than the usual "Track 2" approach. As such, the program is designed for families whose cases typically would be closed following referral to the child welfare agency, without an investigation.

\section{Description of the intervention}

ARS clients receive intensive home visiting from paraprofessionals, the majority of whom have Bachelor-level degrees. Staff are specially trained to assess family strengths, weaknesses, and needs using the California Safety Assessment and the California Family Risk Assessment of the Structured Decision Making (SDM) tool (for description, see: California Department of Social Services, n.d). Together with the family, they develop a Family Care Plan that structures their case management activities and sets goals for family progress in one or more domains of family life. Staff broker resources that address family needs, they assess and support 
the development of positive parent-child relationships, and they offer social support and connections to other forms of positive social support networks. In addition, staff are able to provide limited material supports (e.g., diapers, gift cards for groceries, etc.) to help families meet basic needs. Services are typically offered on a weekly basis with home visitors providing one to two visits per week of one to two hours duration. Services are offered for 9 months, with some families provided an extension of services up to 12 months. The ultimate goal of ARS is to promote child safety and family stability, reduce the likelihood of future child welfare involvement, and pursue positive child development.

ARS has several unique attributes that make it worthy of study. First, ARS was implemented early (in May 2002), making it the first pilot DR program implemented in California. Second, the ARS approach is unique compared with Differential Response programs in other states and California counties with regards to staffing (by paraprofessionals), service delivery strategy (intensive home visiting), and point of intervention (cases screened out of the traditional child welfare system). Third and finally, ARS is implemented in three diverse, lowincome neighborhoods, with services provided by a different agency in each neighborhood. As such, ARS is highly tailored to the neighborhood context. As Differential Response involves connecting families to local formal and informal resources, the ability of agency staff to form connections with other service providers and neighborhood institutions is a key element of program design (See Conley, 2007 andConley \& Berrick, 2008 for a more thorough discussion of the program and its customized approach to unique neighborhood settings).

\section{Methods}

Client outcomes were examined using a quasi-experimental static-group comparison design (Hoyle et al., 2002). An experimental design was not possible because the researchers 
could not control assignment of clients to the treatment. Data were collected on clients who were referred to and accepted services at the most established ARS program site from May, 2002 to December, 2006 and were followed through February, 2008 to allow for 9 months of services plus an additional 5 months of observation for the last families who entered the study. Families were eligible for the study if they were reported to the Alameda County Child Abuse hotline between the periods of May 1, 2002 and December 31, 2006, but were "evaluated-out," signifying that their case was immediately closed with no follow-up investigation, assessment, or services offered. Families were offered ARS services if they had at least one child age 5 or younger, or the mother was pregnant, and they resided in certain zip codes. Of all evaluated-out cases eligible for and approached for program participation ( $N=565), 44 \%$ accepted ARS services $(n=250)$ and were eligible for inclusion in the treatment group. From this group, only one sibling (from a sibling group) was kept in the analysis to preserve the statistical assumption of independence, making this a family-level, not child-level, analysis. The final sample size for the treatment group is $N=134$. The comparison group $(N=511)$ is comprised of families who met the same eligibility criteria but who were not referred to the ARS program due to program capacity.

The dependent variable is subsequent involvement with the child welfare system for children who were retained for ARS services, compared to similar children not offered services. The dependent variable is operationalized as a re-report, investigated re-report, and substantiated re-report. For the purposes of this study, failure events were assessed nine months or later postreferral (the length of the ARS intervention). Measuring the outcome post-service rather than post-referral minimizes surveillance bias (Socolar, Runyan, \& Amaya-Jackson, 1995), since ARS home visitors are in their clients' homes weekly and must report incidents of child 
maltreatment. The lasting effects of service completion are also evaluated by the choice of this timeframe. The independent variable is participation in ARS services. Other factors, such as child's ethnicity, gender, and number of prior reports, were examined as potential confounders of treatment effects.

Data were compiled by the Alameda County Social Services Agency (SSA) and shared with researchers for analysis. Data were drawn from the administrative records of the Child Welfare Services Case Management System (CWS/CMS). The referral identifier numbers for all families who agreed to receive ARS services were checked for records of contacts with the child welfare system 270 days post-referral, which approximated the length of time for the ARS intervention. The same was done for comparison group families. Cases marked as "retained" by the ARS agency were included in the treatment sample, indicating that the family had been assessed and had accepted services. Some cases had missing data and were unable to be included in the analysis, and a small percentage of cases were labeled as "referred," meaning that families were given information on community resources by the public child welfare agency worker and were not referred to ARS. Another group of cases were labeled as "returned," meaning that families refused services, families could not be located, or families' cases were sent back to the county social services agency for further action, if any. See Table 1 for information on all cases referred to the ARS program during the study timeframe.

Data for the treatment and comparison groups were then prepared for analysis. One child from each sibling group was retained in the sample, for both treatment and comparison groups, alternating between the oldest and youngest sibling age five or younger. The date of referral to ARS for the treatment group was coded as the initial date of service, and date of screened-out report was coded as the start date for the comparison group. The first re-report of child 
maltreatment that fell after the nine month mark (approximated as 270 days) was selected as the failure event. Those study participants who did not experience a subsequent re-report remained in the sample until the date which marked the end of the study (February 14, 2008). Data for only the first re-report were included for each client. In some cases, there was more than one rereport in a short period of time. Following the convention of the county, two reports within a five day span were considered to reflect the same incident of maltreatment. The most serious agency response within the five day period was counted as the failure event, according to the following hierarchy used by the county: immediate investigation, 10 day investigation, or no investigation/evaluated out. Data on the maltreatment report, client demographics, and prior child welfare history were included in the final analysis file. Failure events were coded as binary data ( 1 for yes, 0 for no) for re-report, investigation of re-report, and substantiation of re-report. Quality assurance checks were made on sample construction and data coding by a graduate student research assistant. Analyses of entries to out-of-home care were not included due to the very small number of entries.

\section{Data analysis}

Survival analysis (also known as time-to-event analysis) was used to compare the rates of re-report, investigated re-report, and substantiated re-report for the treatment and comparison groups. Survival analysis is a type of analysis used for data that conform to a structure with a defined time origin and end-point. Time origins often represent participant recruitment into a study, the beginning of participation in a treatment program, or diagnosis with a medical condition. The end point is generally considered a "failure" event and in medical research may represent death (hence the term "survival analysis"). For longitudinal event data, survival analysis is superior to ordinary multiple regression in its capacity to account for censored data 
(for those cases in which the event of interest did not occur in the observed timeframe) and time varying explanatory variables (Allison, 1984).

The hazard ratio is reported with its significance level for each type of failure event (child maltreatment re-report, investigated re-report, and substantiated re-report). It compares the hazard rates of the treatment and comparison groups. The hazard rate is the probability that the failure event, if it has not already occurred, will occur in the next time interval, divided by the length of the time interval. The time interval is made very short to provide a practically instantaneous rate. The Cox Proportional Hazard Model used in this analysis assumes that the hazard ratio is constant over time (Spruance, Reid, Grace \& Samore, 2004). In this case, the hazard rate represents the probability that a family, given treatment, will experience the failure event, given that they have yet to have had an event (re-report, investigation, or substantiated rereport).

The hypothesized effects of ARS treatment on subsequent child welfare system involvement are somewhat complex due to the potential bias that may arise from increased surveillance of families referred to the program, even post-program completion. ARS clients may be more likely to be re-reported than members of the comparison group because they may be better connected to community resources (and thus mandated reporters) as a result of their contact with the ARS provider. For this reason, treatment may not reduce re-report but may increase it (Chaffin et al., 2001). The anticipated effects are clearest in the case of substantiation, the finding that a report meets the statutory definition of child maltreatment, as this outcome is less likely to be influenced by families' surveillance within the community. Due to the small sample size and the rarity of its occurrence, however, this study has limited statistical power to address the outcome of substantiation. 


\section{Results}

\section{Descriptive statistics}

Chi Squares were used to examine relations between group status (treatment/comparison group) and demographic and child welfare involvement variables. ARS services lasted a mean number of 250 days, with $81 \%$ of parents completing eight or more months of service. Parents completing services (i.e., treatment group) were different from comparison parents along a few dimensions (see Table 2). The treatment group had a smaller proportion of Hispanics and African Americans, and a larger proportion of families with unknown ethnicity. The treatment group had a higher proportion of infants ages 1-2. A significant difference between the treatment and comparison group is also contact with the child welfare system prior to ARS referral. Almost all of the treatment group but somewhat less than a third of the comparison had a prior report

These numbers seem too dramatically different for mere coincidence, suggesting that either hotline screeners may have more frequently referred to ARS clients with a history of prior reports or families with known histories to child welfare were more open to engaging in ARS services to address their longstanding family problems. Child welfare involvement data were available for about two-thirds of cases of those cases referred to ARS during the study period but "returned," meaning that they were unable to be contacted or refused services. Problems with data matching for the remaining cases resulted from errors arising from the quality of data provided during the referral process, such as name misspelling and use of different names. A comparison of the available data on the returned cases and those that accepted and were retained for services suggests that significantly fewer of the "returned" cases had child maltreatment reports prior to their referral to $\operatorname{ARS}(41 \%$ vs. $96 \%) \chi^{2}(1, N=314)=102.26, p<.001$. It appears 
that families who had prior reports may have been either easier to find (i.e. could be contacted) and/or accepted ARS services at higher rates. Because re-report is associated with being retained for services in the ARS program as well as the outcomes of re-report, investigated re-report, and substantiated re-report, it is likely to be a confounder in the analysis.

Risk scores from the Structured Decision Making tool (SDM) were available for ARS clients, though not for the comparison group; risk scores therefore were not included in the statistical models. ARS home visitors, together with their clinical supervisor, complete the SDM during an initial meeting with families. For the treatment sample, $n=3(2 \%)$ were identified as low risk, $n=64(48 \%)$ as moderate risk, $n=52(39 \%)$ as high risk and $n=12(9 \%)$ as very high risk, with $n=3$ (2\%) missing a risk score (for more information on SDM, see Johnson, 2004).

\section{Outcomes}

Re-reports were made for ARS cases during treatment: approximately one-quarter of both treatment and comparison group families had one or more re-reports -defined as the first 270 days following the first referral for comparison group families. Difference in allegation incidence and types were not statistically significant.

For the period post-ARS referral for the treatment group, and post the equivalent 270 day time frame for the comparison group, rates of re-report, investigated re-report, and substantiated re-report were fairly similar, with a few exceptions. In both cases, about a third of the sample experienced a re-report. Re-report tended to occur sooner among the treatment group: the ratio of the overall mean time (not excluding ARS participation or equivalent timeframe) to re-report for the treatment and comparison groups is 560:755 days. General neglect and physical abuse were the most common re-report allegation types for both groups. For those cases with available 
risk scores (131 of the $N=134$ treatment sample), $42 \%$ of very high risk cases, $44 \%$ of high risk cases, $20 \%$ of moderate-risk cases, and $0 \%$ of low-risk cases had a re-report.

Investigations following a re-report were also relatively similar for the treatment and comparison group; differences were not statistically significant. The types of investigations and investigation conclusions were also quite similar. General neglect was the most frequently substantiated allegations for both groups.

Outcome: Re-report. First, a nonparametric approach, which makes no assumptions regarding time to event distribution, was used to examine the data for re-report as an outcome. A log-rank test was conducted to see if there was evidence that one of the groups was failing faster. The null hypothesis is that the survivor functions of the two groups are the same. There was no evidence to reject the null $\left.\chi^{2}(1, N=645)=0.09, p=0.77\right)$. Table 3 shows the results of parametric models for the outcome of re-report.

In the first wave of parametric analysis, a Cox regression was fitted with treatment and other covariates. The initial model with treatment alone was not significant, , suggesting no effect of treatment on re-report. A series of models were examined considering treatment with a single variable, in order to examine the change in hazard ratio. None were significant except for unknown ethnicity, Caucasian ethnicity, and prior reports; these analyses suggest an increased hazard for the outcome of re-report associated with treatment and Caucasian ethnicity and treatment and prior reports, and a decreased hazard for re-report associated with treatment and unknown ethnicity. When adjusting for prior reports, removing the difference in the hazard ratio due to prior reports, the hazard ratio for treatment dropped to $H R(3, N=645) 0.69[0.17,2.89]$, $p=0.62$ ). The treatment group appears to fail faster than the comparison group, but the difference 
is not statistically significant. Plot is based on Cox model, with prior reports set to average value (see Figure 1).

Additional analyses were conducted to examine the possible contributions of prior reports and allegation types. The proportion of children with prior reports is significantly higher in the treatment group than in the comparison group, and number of prior reports may affect both assignment to treatment and the outcome of re-report. A model was constructed with treatment (binary variable, $1=$ treatment), prior reports (binary variable, $1=$ =prior report), and an interaction term (cross product of treatment and prior reports), keeping both main effects. The results were not significant. An analysis examining re-reports among cases initially reported for general neglect and physical abuse found no significant differences in re-report rates by maltreatment type, providing no evidence for a differential effect of treatment by maltreatment type.

Outcomes: Investigated re-report \& substantiated re-report. The next series of analyses examined whether treatment affects the likelihood of an investigation or substantiation following a report for maltreatment. For investigation as an outcome, the log-rank test was not significant and therefore the null hypothesis of equality of survival functions cannot be rejected. Fitting parametric models to the data with investigation as the outcome yielded similar findings to the re-report analyses. For the unadjusted model, there was no statistically significant effect of treatment on the risk of investigation. Models fit with demographic variables were not significant. Rates of investigation were again dependent on whether families had a history of child maltreatment reports, but differences between groups were not significant. Similar patterns were evident for substantiation, although substantiation was a rare event, so the power to detect differences between the two groups is very low. 


\section{Discussion}

\section{Major findings}

This study compared rates of re-report and investigated re-report following a paraprofessional-delivered, 9-month, home visiting program (ARS) for a group of families with children ages 0-5 who were assessed out of the child welfare system following a referral for child maltreatment. Using survival analysis, treatment group children were compared to children eligible for services, but denied due to program capacity. Findings suggest no statistically significant differences between groups on the likelihood of a re-report following program participation, on the timing of maltreatment reports following participation, or on report investigations. Although data on report substantiations were available, the small sample size precluded the opportunity to conduct statistical analyses. Caution should be observed when drawing conclusions from the research, however, in light of the methodological challenges associated with this study.

\section{Limitations}

The ability to draw strong conclusions from this study is hampered by issues relating to internal validity such as selection bias and sample size, and measurement error. Child maltreatment reports have a low base rate, even among high risk populations (Guterman, 1997). Particularly when examining substantiation, a rare outcome, the small sample size in this study made it impossible to detect significant differences between groups. Therefore, differences that might have been detected with a larger sample could not be captured with these data.

The study also suffers from selection bias. Although staff at the county agency indicated that comparison group families were not offered the intervention due to program capacity, important differences in the treatment and comparison group were detected. Almost all (96\%) of 
the clients who accepted ARS services had a prior child maltreatment referral compared to $34 \%$ of families in the comparison group. It is possible that hotline screeners referred families to the ARS program more frequently when they observed prior reports, and it is equally possible that child welfare staff referred families on a first-come-first-served-basis, but that families with prior child maltreatment reports were more likely to accept ARS services.

Under ideal research environments, families in both conditions would be assessed for risk prior to assignment to treatment or comparison condition. Because this study was designed with many accommodations made to the public agency, these data were not available for the comparison group - a reflection on the hazards associated with real-world research, but a significant limitation for future researchers to consider. To the extent we were able to control for family risk prior to the intervention, we ran our analyses controlling for prior child maltreatment report as an indicator of elevated risk. This is, of course, a crude assessment at best, but with access only to administrative data for this study, it was the only variable available to meet our objectives. In retrospect it is also clear that a comparison group might have been drawn using Propensity Score Matching strategies. Such an approach using a range of variables might have yielded a comparison group with a greater number of similarities to the treatment group. Without access to the source data, however, these opportunities could not be pursued. In short, efforts were made to determine the equivalency of the two groups, but underlying differences between the groups may indeed exist, driving some of the outcomes observed in the study more than the intervention itself.

Selection bias may have also emerged due to the voluntary aspect of ARS services. Clients who were more troubled may have been more likely to opt for treatment, or alternatively, clients who were better prepared to change their parenting may have chosen to participate. Non- 
random assignment could have biased the sample in other unknown ways as well. Intervention types and dosage were not controlled, as they might have been for a rigorous randomized trial. The lack of control over assignment and exposure to treatment constitute threats to internal validity; they also reflect the significant challenges associated with studying this program. Future researchers can benefit from the lessons learned in carrying out this evaluation.

The real-world context of child welfare means that agencies are often over-extended with too many clients to serve, given typical agency resources. As such, in this study as in other studies of DR, this sample did not exclusively include families at low- to moderate-risk. Almost half of the sample was identified as either "high risk" or "very high risk" by ARS staff. We believe this client composition likely reflects the fact that very troubled families are regularly brought to the attention of child welfare agencies, and even these families often are turned away from services. Future studies that can examine DR program effects only for those clients for whom the intervention was designed would be a welcome addition to the literature, however rereport rates for families at low- to moderate-risk were especially low, suggesting that they might not have been at risk for future maltreatment but could instead benefit from services with a different outcome objective.

In line with other studies of DR, this project examines child welfare system involvement as a proxy for future maltreatment. But child welfare system involvement may not necessarily equate with child maltreatment prevention, raising the question of construct validity. Child maltreatment has been described as an "iceberg phenomenon:” only a small portion of actual cases are visible to the system, while the majority remains hidden. The hidden nature of child maltreatment may affect the likelihood of initial reports and re-reports, as well as the trajectory of later child welfare system involvement. A single report may not accurately capture a family's 
level of risk and need for intervention (Wolock, et al., 2001). Increased surveillance may occur in programs emphasizing weekly contact with a mandated reporter and referral to community services staffed by mandated reporters (Guterman, 1997). Such programs may prevent maltreatment recurrence in some cases while promoting early detection in others, but the early detection effects could mask the overall beneficial impact of services (Olds \& Kitzman, 1993). At the same time, surveillance bias is not a catch-all excuse for null findings. Studies which have accounted for this source of bias in statistical modeling have typically found that its unique contribution is small (Chaffin \& Bard, 2006).

The administrative data used to examine client outcomes are prone to certain types of errors and limitations. When client identifiers were not available, child names and demographic descriptors were used to identify ARS clients in the CWS/CMS administrative database. Cases could have been misidentified during this process. Further, some clients believed to have been referred to ARS as part of the "returned" group could not be located in the CWS/CMS database. Perhaps even more importantly, reliance on administrative child welfare data limits the scope of analysis. Only outcomes associated with child welfare system involvement could be examined due to lack of data on the comparison group in 'softer' domains, such as child health and parentchild interaction. Reduction of researcher control over data completeness and variable measurement is characteristic of research on administrative child welfare datasets (Drake \& Jonson-Reid, 1999).

\section{Implications}

Keeping in mind the limitations discussed above, this study suggests important implications for practice and for future research. Findings of a weak effect of treatment on subsequent maltreatment are in line with the literature on child maltreatment prevention and on 
Differential Response interventions. In Geeraert and associates' (2004) meta-analysis of 19 studies, and in MacLeod and Nelson's (2000) meta-analysis of over 50 programs, positive results of programs on maltreatment prevention were found, but the overall effect size (about 0.20 in both reviews) would be considered small by conventional standards. The majority of studies conducted on Differential Response also have found that re-report rates are similar for treatment and comparison groups six months after DR services (Center for Child and Family Policy, 2004; English et al., 2000; U.S. Department of Health and Human Services, 2005).

These limited findings vis-à-vis maltreatment prevention certainly suggest the need for additional research built on tighter controls in clinical trials. Recent efforts by the American Humane Association to fund a handful of studies on Differential Response, ${ }^{1}$ all demanding strict adherence to random selection and assignment, will provide a deeper understanding of the promise of DR for preventing maltreatment and supporting positive family development among Track 2 cases. In the meantime, if the findings on DR from current studies are taken as a whole, they suggest certain limitations on the robust effects of maltreatment prevention.

The limited findings from this study on the effects of Track 1 Differential Response raise several questions about this potential maltreatment prevention approach. First, the ARS program examined in this study offered a relatively intensive, long-term, semi-structured intervention for troubled families. This stands in contrast to many DR approaches now gaining widespread support across the country, many of which offer little more than referrals to community resources. Whether or not a program such as this is sufficiently robust to change family patterns of childrearing is a question that bears future study. Second, staff delivering ARS were community paraprofessionals - individuals attempting to change sometimes entrenched patterns

\footnotetext{
${ }^{1}$ See: Children's Bureau-funded National Quality Improvement Center on Differential Response in Child Protective Services. http://www.differentialresponseqic.org/
} 
of parenting and family dysfunction. While some evidence suggests professionally supported community members can help to support and strengthen many families (Olds et al., 2002), the evidence base for their effectiveness in preventing maltreatment is weak. And third, although a large majority of families who engaged in services stayed with their home visitor for eight months or longer, more than half of families who were offered ARS voluntary services did not opt to participate in the program. This may suggest that the intervention itself is considered sufficiently non-intrusive and/or helpful that families do not rebuff their home visitor, but it also raises questions about the financial viability of a program whose resources are spent heavily on attempting to engage clients who ultimately decline services. If programs such as ARS show few effects on preventing maltreatment, it is important to ask whether they instead serve a different purpose for child welfare agencies and for families.

For years, public child welfare agency administrators have protested that the principal tool available to help families during times of crisis was child removal and subsequent foster care. For some families, this intervention was too intrusive and too severe, but lacking other alternatives and trying to manage future risk to the child, agencies were often reluctant to leave high-risk children in the homes of their parents. Other families deemed at low- to moderate-risk of future maltreatment were often closed off from traditional child welfare services, leaving them on their own to identify and enlist informal and formal supports to assist them through their personal or familial challenges. Differential Response was launched, in part, to offer child welfare agencies a larger repertoire of services for families. The opportunities afforded through ARS have indeed given social workers in one public child welfare agency new alternatives for serving families who would otherwise be assessed out and entirely ignored. 
Whether the families targeted for ARS services would have otherwise been removed from their homes or whether they would have maltreated their child in the future is questionable. Indeed, this analysis suggests that up to one-third of these families would have returned to child welfare in the following years through a new child maltreatment referral with or without participation in ARS, and approximately two-thirds would not have had further contact with the child welfare agency. For the families at low- to moderate-risk -- for whom ARS Track 1 services were intentionally designed -- the likelihood of future contact with the child welfare services system were extremely low even without the benefit of ARS. As noted earlier, none of the low risk cases and only $20 \%$ of the moderate risk cases had re-reports post-ARS treatment. It appears that the program was offered to families who needed services of one kind or another, many of whom may have been in crisis when they were reported to the child welfare system, but whose children were not at substantial risk of removal or other deeper child welfare involvement. For these families, the program aimed to improve family circumstances, promote stronger parent-child relationships, and avert future contact with the child welfare system. With regard to the latter of these goals, like other Differential Response programs across the country, this study suggests that the ARS program may not have made a substantial impact on recidivism. Therefore, to characterize Differential Response as a "child maltreatment prevention program" may be a misnomer and in marketing the program more widely may eventually dampen its widespread adoption due to its "failure" on this account.

With regard to improving family circumstances and promoting parent-child relationships, this study can provide only a crude assessment. Findings from the larger study (not reported here) that included focus groups with staff and interviews with families suggest that the program offers important benefits to families (Berrick et al., 2009). Many families attest to the 
importance of social support, connection to community resources, assistance with meeting basic needs, and renewed capacities for attending to their children's needs. While these family support endeavors may not be sufficiently robust to maintain family health and prevent maltreatment, they are clearly important to families during a time of significant stress and substantial need. Therefore, as a child maltreatment prevention program, Track 1 of Differential Response may not hold great promise. As an important mechanism for offering family support, however, Differential Response may be an additional tool child welfare agencies may use to help families as they struggle to raise their children. Future studies should test these important family outcomes. 


\section{References}

Allison, P.D. (1984). Event history analysis. Quantitative Applications in the Social Sciences Series. M.S. Lewis-Beck (Ed.). Newbury Park: Sage Publications.

Baird, C. \& Wagner, D. (2000). The relative validity of actuarial- and consensus-based risk assessment systems. Children and Youth Services Review, 22 (11/12), 839-871.

Baird, C., Wagner, D., Healy, T., \& Johnson, D. (1999). Risk assessment in child protective services: Consensus and actuarial model reliability. Child Welfare, 78 (6), 723-748.

Berrick, J.D., Branom, C., Conley, A., Price, A. (2009, July). Assessing Alternative and Differential Response: Implications for Social Work Practice in Diverse Communities. Executive Summary. Berkeley, CA: Center for Child and Youth Policy, University of California at Berkeley. Retrieved from the California Social Work Education Center (CalSWEC) website:

\section{http://calswec.berkeley.edu/calSWEC/08_FE_2009_ExecSum_DR_070809.doc}

California Department of Social Services (n.d). Structured decision making. Retrieved from the California Department of Social Services website:

http://www.dss.cahwnet.gov/cfsweb/PG1332.htm

Center for Child and Family Policy (2004). Multiple Response System (MRS) evaluation report to the North Carolina Division of Social Services (NCDSS). Retrieved from the Center for Child and Family Policy website: http://www.pubpol.duke.edu/centers/child

Chaffin, M., Bonner, B. L., \& Hill, R. F. (2001). Family preservation and family support programs: Child maltreatment outcomes across client risk levels and program types. Child Abuse and Neglect, 25, 1269-1289. 
Chaffin, M. \& Bard, D. (2006) Impact of intervention surveillance bias on analyses of child welfare report outcomes, Child Maltreatment 11 (4), 301-312.

Child Welfare Stakeholders Group (2003). CWS redesign: The future of California's child welfare services final report. Retrieved from the California child welfare services redesign website: http://www.cwsredesign.ca.gov/res/pdf/CWSReport.pdf

Collett, D. (1994). Modeling survival data in medical research. Texts in Statistical Science Series. C. Chatfield and J. V. Zidek (Eds.). New York: Chapman \& Hall.

Conley, A. (2007) Differential response: A critical examination of a secondary prevention model. Children \& Youth Services Review, 29, 1454-1468.

Conley, A. \& Berrick, J.D. (2008). Implementation of differential response in ethnically diverse neighborhoods: A public-private partnership. Invited article for special edition on Differential Response. Protecting Children, 23 (1-2), 30-38.

Drake, B. \& Jonson-Reid, M. (1999). Some thoughts on the increasing use of administrative data in child maltreatment research. Child Maltreatment, 4, 308-315

English, D. J., Marshall, D. B., Brummel, S., \& Orme, M. (1999). Characteristics of repeated referrals to child protective services in Washington state. Child Maltreatment, 4(4), 297-307.

English, D. J., Wingard, T., Marshall, D., Orme, M., \& Orme, A. (2000). Alternative responses to child protective services: Emerging issues and concerns. Child Abuse and Neglect, 24 (3), 375-388.

Foundation Consortium (2005). Differential response in California. Retrieved from the Foundation Consortium website: http://www.foundationconsortium.org/pdf/cws/dr_overview.pdf 
Geeraert, L., Van den Noortgate, W., Grietens, H., \& Onghena, P. (2004). The effects of early prevention programs for families with young children at risk for physical child abuse and neglect: A meta-analysis. Child Maltreatment, 9 (3), 277-291.

Guterman, N. (1997). Early prevention of physical child abuse and neglect: Existing evidence and future directions. Child Maltreatment, 2 (1), 12-34.

Hoyle, R.H., Harris, M.J. \& Judd, C.M. (2002) Research methods in social relations, $7^{\text {th }}$ edition. Belmont, CA: Wadworth/Thomas Learning Inc.

Johnson, W. (2004). Effectiveness of California's child welfare Structured Decision Making (SDM) model: A prospective study of the validity of the California family risk assessment. Retrieved from http://www.childwelfare.gov/systemwide/assessment/approaches/decision.cfm Kaplan, C., \& Merkel-Holguin, L. (2008). Another look at the National Study on Differential Response in Child Welfare. Protecting Children, 23 (1-2), 5-23.

Kirk, R.S. (2008). Development and field-testing of a family assessment scale for use in child welfare practice settings utilizing Differential Response. Protecting Children, 23, (1-2), 7188.

Loman, L.A. \& Siegel, G.L. (2004a). Minnesota alternative response evaluation final report. Retrieved from the Institute of Applied Research website: http://iarstl.org/papers/ARFinalEvaluationReport.pdf

Loman, L. A. \& Siegel, G.L. (2004b). Differential response in Missouri after five years. Retrieved from the Institute of Applied Research website: http://iarstl.org/papers/MODiffResp2004a.pdf 
Marshall, D.B. \& English, D.J. (1999). Survival analysis of risk factors for recidivism in child abuse and neglect. Child Maltreatment, 4, 287-296

MacLeod, J., \& Nelson, G. (2000). Programs for the promotion of family wellness and the prevention of child maltreatment: a meta-analytic review. Child Abuse and Neglect, 24 (9), 1127-1149.

McCurdy, K. (2000). What works in nonmedical home visiting: Healthy Families America. In M.P. Kluger, G. Alexander \& P.A. Curtis (Eds.), What Works in Child Welfare (pp. 45-56). Washington, D.C.: CWLA Press.

National Child Welfare Resource Center for Family-Centered Practice (2001). Examples of differential response in several states making differential response. Best Practice Next Practice. Spring: 7-24. Retrieved from http://www.hunter.cuny.edu/socwork/nrcfcpp/downloads/newsletter/BPNPSpring01.pdf

Needell, B., Webster, D., Armijo, M., Lee, S., Dawson, W., Magruder, J., Exel, M., Glasser, T., Williams, D., Zimmerman, K., Simon, V., Putnam-Hornstein, E., Frerer, K., CuccaroAlamin, S., Winn, A., Lou, C., \& Peng, C. (2009). Child welfare services reports for California. Retrieved from University of California at Berkeley Center for Social Services Research website: http://cssr.berkeley.edu/ucb_childwelfare

Olds, D. L. \& Kitzman, H. (1993). Review of research on home visiting for pregnant women and parents of young children. The Future of Children, 3 (3), 53-92.

Olds, D., Robinson, J., O'Brien, R., Luckey, D., Pettitt, L., Ng, R., Sheff, K., Korfmacher, J., Hiatt, S., Talmi, A., Henderson Jr, C. (2002). Home visiting by paraprofessionals and by nurses: A randomized, controlled trial. Pediatrics, 110(3), 486-497. 
Schuerman, J.R., Rzepnicki, T.L. \& Littell, J.H. (1994). Putting families first: An experiment in family preservation. New York: Aldine de Gruyer.

Spruance, S.L., Reid, J.E., Grace, M., Samore, M. (2004, August). Hazard ratio in clinical trials. Antimicrobial Agents and Chemotherapy, 48 (8), 2787-2792.

Waldfogel, J. (1998). Rethinking the paradigm for child protection. The Future of Children, 8 (1), 104-119.

Waldfogel, J. (2000). Reforming child protective services. Child Welfare, 79 (1), 43-57

Wolock, I., Sherman, P., Feldman, L.H., \& Metzger, B. (2001). Child abuse and neglect referral patterns: A longitudinal study. Children \& Youth Services Review, 23 (1), 21-47.

US Department of Health and Human Services, Administration for Children and Families/ Children's Bureau and Office of the Assistant Secretary for Planning and Evaluation (2005). Alternative responses to child maltreatment: Findings from NCANDS. Washington, DC: U.S. Government Printing Office. Retrieved from the Office of the Assistant Secretary for Planning and Evaluation website: http://aspe.hhs.gov/hsp/05/child-maltreat-resp/ Virginia Department of Social Services. (2003). Evaluation of the Differential Response System. Retrieved from http://www.bscca.org/Lists/Weekly\%20Highlights/Attachments/62/EvalutationOutcomes_VA_DR.pdf 
Table 1

All Cases Referred to ARS from May 1, 2002 to December 31, 2006

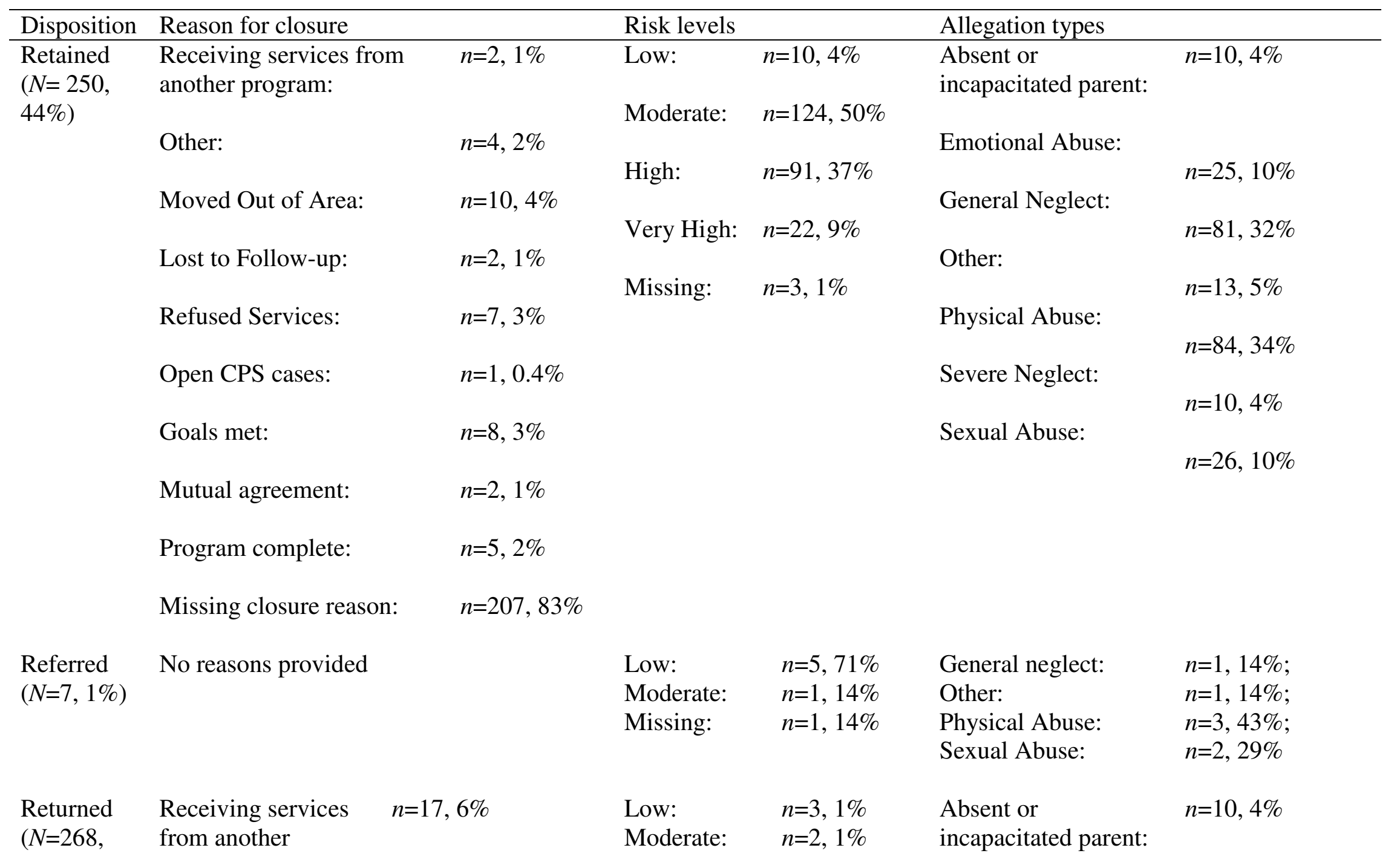


$47 \%)$

\section{program:}

Other:

Moved Out of Area:

Lost to Follow-up:

Refused Services:

Open CPS cases:

Missing closure

reason:

$n=27,10 \%$

$n=25,9 \%$

$n=79,29 \%$

$n=94,35 \%$

$n=2,1 \%$

$n=24,9 \%$

$\begin{array}{llll}\text { High: } & n=2,<1 \% & \text { Emotional Abuse: } & \\ \text { Very High: } & n=2,<1 \% & \text { General Neglect: } & n=30,11 \% \\ \text { Missing: } & n=257,96 \% & \text { Other: } & n=108,40 \% \\ & & \text { Physical Abuse: } & n=3,1 \% \\ & & \text { Severe Neglect: } & n=75,28 \% \\ & & \text { Sexual Abuse: } & n=7,3 \% \\ & & & n=35,13 \%\end{array}$

Not available

Missing

Not available

$(N=39$,

$7 \%)$

$\begin{array}{ll}\begin{array}{l}\text { Absent or } \\ \text { incapacitated parent: }\end{array} & n=5,13 \% \\ \text { Emotional Abuse: } & \\ \text { General Neglect: } & n=7,18 \% \\ \text { Other: } & n=16,41 \% \\ \text { Physical Abuse: } & n=1,3 \% \\ \text { Severe Neglect: } & n=5,13 \% \\ \text { Sexual Abuse: } & n=1,3 \% \\ & n=4,10 \%\end{array}$


Table 2

Treatment and Comparison Group Demographics and Child Welfare Involvement

\begin{tabular}{|c|c|c|c|c|}
\hline \multirow[t]{2}{*}{ Variable } & \multicolumn{2}{|c|}{$\underline{\text { Treatment group }}$} & \multicolumn{2}{|c|}{ Comparison group } \\
\hline & $\mathrm{N}$ & Percent & $\mathrm{N}$ & Percent \\
\hline Male & 71 & 53 & 282 & 55 \\
\hline Primary ethnicity-Hispanic* & 37 & 28 & 199 & 39 \\
\hline Primary ethnicity-African American** & 15 & 11 & 109 & 21 \\
\hline Primary ethnicity-Caucasian & 28 & 21 & 121 & 24 \\
\hline Primary ethnicity-Other & 18 & 13 & 49 & 10 \\
\hline Primary ethnicity-Unknown** & 36 & 27 & 33 & 6 \\
\hline Age-Infant* & 61 & 46 & 180 & 35 \\
\hline Age-Preschooler** & 60 & 45 & 138 & 27 \\
\hline Age-Kindergartner** & 12 & 9 & 193 & 38 \\
\hline Prior child maltreatment report $* * *$ & 129 & 96 & 175 & 34 \\
\hline $\begin{array}{l}\text { Re-report during ARS treatment or } \\
\text { equivalent timeframe }\end{array}$ & 32 & 24 & 128 & 25 \\
\hline $\begin{array}{l}\text { Re-report allegation during ARS } \\
\text { treatment: physical abuse }\end{array}$ & 12 & 38 & 35 & 29 \\
\hline $\begin{array}{l}\text { Re-report allegation during ARS } \\
\text { treatment: general neglect }\end{array}$ & 6 & 19 & 36 & 30 \\
\hline Re-report & 42 & 32 & 163 & 32 \\
\hline Re-report allegation: neglect & 12 & 29 & 60 & 37 \\
\hline Re-report allegation: physical abuse & 17 & 40 & 50 & 31 \\
\hline Investigated re-report & 29 & 69 & 100 & 61 \\
\hline
\end{tabular}


Community-based child abuse prevention 33

Investigation type: immediate

Substantiation

Substantiated allegation: general neglect
$13 \quad 45$

$7 \quad 24$

43
$34 \quad 34$

$18 \quad 18$

7

Note. ${ }^{*} p<.05 * * p<.01 * * * p<.001$ 
Table 3

Parametric Models for Outcome of Re-report

\begin{tabular}{|c|c|c|c|}
\hline Variables & Hazard Ratio & $95 \% \mathrm{CI}$ & $\mathrm{p}$ \\
\hline Treatment alone & 1.05 & {$[0.75,1.48]$} & 0.77 \\
\hline Treatment and male & 0.98 & {$[0.75,1.29]$} & 0.92 \\
\hline Treatment and Hispanic & 0.98 & {$[.74,1.31]$} & 0.91 \\
\hline Treatment and African American & 0.84 & {$[0.58,1.22]$} & 0.37 \\
\hline Treatment and Caucasian** & 1.49 & {$[1.09,2.01]$} & 0.01 \\
\hline Treatment and ethnicity-other & 0.99 & {$[0.63,1.57]$} & 0.99 \\
\hline Treatment and ethnicity-unknown* & 0.55 & {$[0.32,0.95]$} & 0.03 \\
\hline Treatment and infant & 0.90 & {$[0.68,1.20]$} & 0.48 \\
\hline Treatment and preschooler & 1.14 & {$[0.85,1.53]$} & 0.38 \\
\hline Treatment and kindergartner & 0.99 & {$[0.73,1.34]$} & 0.96 \\
\hline $\begin{array}{l}\text { Treatment and prior child } \\
\text { maltreatment report } * * *\end{array}$ & 1.80 & {$[1.33,2.45]$} & 0.001 \\
\hline $\begin{array}{l}\text { Treatment and initial allegation- } \\
\text { general neglect }\end{array}$ & 1.05 & {$[0.75,1.48]$} & 0.77 \\
\hline $\begin{array}{l}\text { Treatment and initial allegation- } \\
\text { physical abuse }\end{array}$ & 1.05 & {$[0.75,1.47]$} & 0.79 \\
\hline \multicolumn{4}{|c|}{$\begin{array}{l}\text { Note. All models had degrees of freedom equal to } 2, \mathrm{~N}=645 \text { except for the first without } \\
\text { covariates which was } 1, \mathrm{~N}=645 \text {. }\end{array}$} \\
\hline
\end{tabular}


Figure 1:

Estimated Survival Functions by Treatment, Re-report as Failure, Adjusted for Prior Reports

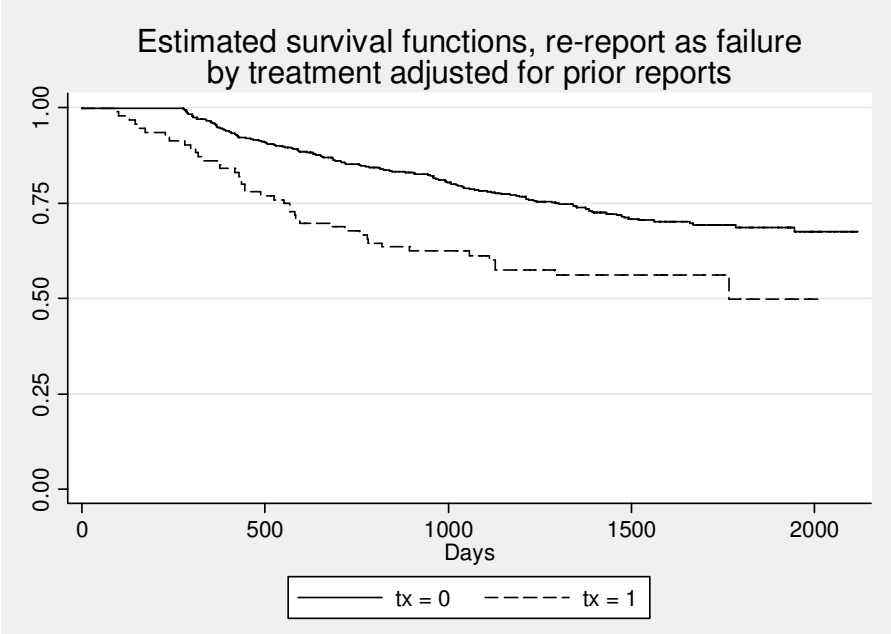

Note. Plots are based on Cox model, with prior reports set to average value. $\mathrm{Tx}=1$ represents the treatment group, $\mathrm{tx}=0$ represents the comparison group. Confidence intervals not shown. Day one is the date of referral to ARS for the treatment group and the date of the index report for the comparison group. 